\title{
Off-clamp robotic-assisted partial nephrectomy
}

\author{
Alec J. Wright ${ }^{1}$, Aaron M. Potretzke ${ }^{1}$, Jeffrey Larson ${ }^{1}$, Robert S. Figenshau ${ }^{1}$ \\ ${ }^{1}$ Division of Urologic Surgery, Washington University, St. Louis, Missouri, USA
}

\section{INTRODUCTION}

Robotic-assisted partial nephrectomy (RAPN) is an effective option for the management of small renal masses. Off-clamp RAPN has emerged as a method to minimize renal ischemic injury and improve renal functional outcomes. In this video we demonstrate our technique for off-clamp RAPN in a patient with a complex $3.6 \mathrm{~cm}$ hilar tumor.

\section{MATERIALS AND METHODS}

We performed a retrospective review of 187 patients who received off-clamp RAPN between August 2007 and March 2015. Patient demographic information, operative information, perioperative outcomes, and renal functional outcomes were evaluated. The Chronic Kidney Disease Epidemiology Collaboration formula was used to calculate eGFR.

\section{RESULTS}

The 187 patient cohort had a mean $( \pm$ standard deviation) age of $58.8 \pm 11.8$ years and a mean
BMI of $32.2 \pm 8.3 \mathrm{~kg} / \mathrm{m}^{2}$. The mean clinical tumor size was $2.9 \pm 1.6 \mathrm{~cm}$ with a mean nephrometry score of $6.9 \pm 2.1$. There was a mean operative time of $169 \pm 61$ minutes and a mean estimated blood loss of $242 \pm 299 \mathrm{~mL}$. Positive surgical margins occurred in 2 cases (1.1\%). Average hospital length of stay was $2 \pm 1.3$ days, and there were 14 (7.5\%) postoperative complications. Mean percent decline of eGFR was $6.8 \pm 21.4 \%$. The average follow-up was 454 days (15-2195 days) with 1 recurrence (0.53\%) occurring at day 596.

\section{CONCLUSION}

Off-clamp RAPN, which eliminates warm ischemic time, is both safe and effective in the treatment of small renal masses when performed by an experienced surgeon. We have found this technique is appropriate for most tumors amenable to minimally invasive partial nephrectomy.

\section{CONFLICT OF INTEREST}

None declared. 


\section{ARTICLE INFO}

Available at: www.intbrazjurol.com.br/video-section/wright_1044_1045/

Int Braz J Urol. 2016; 42 (Video \#10): 1044-5

Submitted for publication:

July 17, 2015

Correspondence address:

Alec J. Wright, PhD

Division of Urology

Accepted after revision:

January 26, 2016

Washington University School of Medicine 4960 Children's Place Campus Box 8242 St. Louis, Missouri 63110, USA E-mail: wrightal@wusm.wustl.edu 